\title{
Correspondence
}

\section{Benign outcome of hypertensive renal crisis in scleroderma}

SIR, Renal involvement may occur in up to $50 \%$ of patients with scleroderma, with considerable morbidity and mortality. ${ }^{1}$ Before current, aggressive antihypertensive treatment a high proportion of patients who developed renal crisis died within several months of its onset. ${ }^{2-4}$ The prognosis of renal crisis has improved considerably since the introduction of angiotensin converting enzyme inhibitors, ${ }^{4-6}$ though not all patients derive benefit from their use. ${ }^{78}$ We report a patient who survived a hypertensive crisis, responding to antihypertensive treatment, with normal renal function 19 years later.

In 1968 a previously normotensive 42 year old woman with an 18 month history of rapidly progressive scleroderma spreading to involve the anterior chest wall presented after a grand mal convulsion. A severe frontal headache had been present for 24 hours. On admission she was afebrile with a reduced level of consciousness, being responsive only to voice. Blood pressure was $240 / 140$, and fundoscopy showed grade III hypertensive changes. Kernig's sign was positive, and both plantar responses were extensor. There were no other localising neurological signs, and general physical examination was normal.

Laboratory investigations showed haemoglobin $149 \mathrm{~g} / \mathrm{l}$, total leucocyte count $10 \cdot 8 \times 10^{9} /, 92 \%$ neutrophils, platelets $140 \times 10^{9} / \mathrm{l}$, erythrocyte sedimentation rate $9 \mathrm{~mm} / \mathrm{h}$. Serum urea was $10.0 \mathrm{mmol} / \mathrm{l}$ (normal $<6.6 \mathrm{mmol} / \mathrm{l}$ ). Previously, her renal function had been normal with a serum urea of $3.3 \mathrm{mmol} / \mathrm{l}$ and normal urine analysis. Serum electrolytes were normal. The urine sediment showed only 10 erythrocytes per high powered field and $3+$ proteinuria. Glomerular filtration rate and proteinuria were not quantified. Electroencephalography showed features consistent with an organic brain syndrome, with minimal alpha activity and irregular slow waves of $1-6 \mathrm{cps}$. Cerebrospinal fluid examination was normal. No organisms were found on Gram stain or culture. Chest radiograph showed mild cardiomegaly with pulmonary venous congestion, and an electrocardiogram showed evidence of left ventricular strain.

The patient had two further grand mal convulsions in the following 24 hours, which were controlled with phenobarbitone and phenytoin. The hypertension was initially treated with intravenous diazoxide and, later, oral a-methyldopa with rapid control of blood pressure. Her sensorium cleared over the next two days, during which time the proteinuria resolved. There were no neurological sequelae. Rapid sequence intravenous pyelography was normal.

For the next 19 years she was regularly reviewed, with no major change in her cutaneous manifestations. Although mild dysphagia developed, no further visceral involvement occurred. In the 12 months following this episode she developed mild hypertension, which has remained well controlled with atenolol alone over the ensuing 19 years.

In 1986 she developed worsening dysphagia due to an adenocarcinoma of the oesophagus, which was resected without incident. At the time there was no clinical evidence of hypertensive complications, and electrocardiography and chest radiography were normal. Creatinine clearance was estimated to be $72 \mathrm{ml} / \mathrm{min}$ (using a standard calculation which uses age, body weight, and serum creatinine), and serum urea and creatinine were normal. There was no proteinuria, and urine sediment was normal.

This patient fulfills the criteria used by Traub et al for the definition of renal crisis, ${ }^{3}$ with the development of significant proteinuria and raised serum urea, which resolved with control of hypertension. Regrettably, creatinine clearance was not measured, but it is likely that proteinuria and the increase of serum urea represent a primary deterioration in renal function rather than a secondary event due to convulsions or volume depletion. This patient's prolonged survival after renal crisis is unusual, perhaps because renal impairment was mild and of short duration.

Large retrospective series have found renal crisis to develop in $8-10 \%$ of patients with scleroderma. ${ }^{39}$ Malignant hypertension and hyperreninaemia are usually present, ${ }^{3} 5$ 8-10 though renal crisis may occasionally be seen without severe hypertension and with normal plasma renin activity. ${ }^{11}$ As in this patient the rapid development of skin involvement may precede the occurrence of renal crisis. ${ }^{8}$ It appears that no other clinical or laboratory abnormalities are predictive for the subsequent development of renal crisis. ${ }^{8}$ Angiotensin converting enzyme inhibitors may abort the course of renal crisis and significantly decrease the morbidity and mortality from this complication, although there is evidence of a spectrum of response to these agents. ${ }^{712}$ The degree of renal impairment at presentation is of prognostic importance as emphasised by the failure of treatment in patients presenting with established, severe renal insufficiency. ${ }^{11}$ The favourable outcome in our patient may have been due to her early presentation and treatment, before the onset of irreversible renal complications, and supports the practice of aggressive investigation and treatment in this disease, which has led to the greatly improved prognosis of scleroderma renal crisis.

Mark H Arnold is supported by the Arthritis Foundation of Australia.

The Florance and Cope Professorial Department of Rheumatology,

M H ARNOLD The University of Sydney,

Royal North Shore Hospital of Sydney,

St Leonards,

New South Wales 2065,

Australia 


\section{References}

1 Cannon P J, Hassar H, Case D B, et al. The relationship of hypertension and renal failure in scleroderma (progressive systemic sclerosis) to structural and functional abnormalities of the renal cortical circulation. Medicine (Baltimore) 1974; 53: 35- 41 .

2 Medsger T A, Masi A T. Survival with scleroderma. II. A lifetable analysis of clinical and demographic factors in 358 male U.S. veterans. J Chronic Dis 1973; 26: 647-60.

3 Traub Y M, Shapiro A P, Rodnan G P, et al. Hypertension and renal failure (scleroderma renal crisis) in progressive systemic sclerosis: review of a 25 year history with 68 cases. Medicine (Baltimore) 1983; 62: 335-52.

4 Wasner C, Cooke C R, Fries J F. Successful medical treatment of scleroderma renal crisis. $N$ Engl J Med 1979; 229: 873-5.

5 Smith $\mathrm{C} \mathrm{D}$, Smith $\mathrm{R} \mathrm{D}$, Korn $\mathrm{J} \mathrm{H}$. Hypertensive crisis in systemic sclerosis: treatment with the new angiotensin converting enzyme inhibitor MK 421 (enalapril) in captopril-intolerant patients. Arthritis Rheum 1984; 27: 826-8.

6 Barnett A J, Miller M M, Littlejohn G O. A survival study of patients with scleroderma diagnosed over 30 years (1953-1983): the value of a simple cutaneous classification in the early stages of the disease. $J$ Rheumatol 1988; 15: 276-83.

7 Brown E A, McGregor G A, Maini R N. Failure of captopril to reverse the renal crisis of scleroderma. Ann Rheum Dis 1983; 42: 52-3.

8 Thurm R M, Alexander J C. Captopril in the treatment of scleroderma renal crisis. Arch Intern Med 1984; 144: 733-5.

9 Steen V A, Medsger T A, Osial T A, Zeigler G L, Shapiro A P, Rodnan G P. Factors predicting the development of renal involvement in progressive systemic sclerosis. Am J Med 1984; 76: $779-86$.

10 Zawada E T, Clements P J, Furst D A, Bloomer A, Paulus H E, Maxwell M H. Clinical course of patients with scleroderma renal crisis treated with captopril. Nephron 1981; 27: 74-8.

11 Whitman H H, Case D B, Laragh J H, et al. Variable response to oral angiotensin-converting enzyme blockade in hypertensive scleroderma patients. Arthritis Rheum 1982; 25: 241-9.

12 Johnson S J, Spiera H. Development of scleroderma renal failure without severe hypertension: five cases. Arthritis Rheum 1980; 23 (suppl): 698.

\section{Immunisation triggering rheumatoid arthritis?}

SIR, We read with interest the article by Turner-Stokes and Isenberg on immunisation of patients with rheumatoid arthritis (RA) and systemic lupus erythematosus (SLE). ${ }^{1}$ Isolated reports of the onset of SLE following immunisation have occurred, ${ }^{2}$ but we are unaware of similar cases in RA. We have recently observed a patient who developed RA three weeks after a second dose of tetanus toxoid. A 34 year old woman received two doses of tetanus toxoid in November and December 1986. A week after the second dose she developed severe pain with erythema and induration measuring $10 \mathrm{~cm}$ in diameter at the site of injection over the left deltoid muscle. This severe local reaction lasted 10 days. A few days after the erythema and induration started to fade the patient developed a symmetrical inflammatory polyarthritis involving the proximal interphalangeal, metacarpophalangeal, wrist, elbow, shoulder, knee, and the metatarsophalangeal joints. The arthritis was severe with early morning stiffness lasting several hours. There was no past history of arthritis, inflammatory bowel disease, iritis, back pain, psoriasis, or recent infection and no family history ọ̣. inflammatory arthritis.

Investigations in March 1987 showed haemoglobi $149 \mathrm{~g} / \mathrm{l}$, white cell count $8 \times 10^{9} / \mathrm{l}$, platelet count $307 \times 10^{9} / \mathrm{l}$ erythrocyte sedimentation rate (ESR) $17 \mathrm{~mm} / \mathrm{h}, \mathrm{C}$ reactive protein $120 \mathrm{mg} / \mathrm{l}$ (normal range (NR) $<60$ ), albumin $45 \mathrm{~g} /$ 㕄 globulin $33 \mathrm{~g} / \mathrm{l}$ (NR 18-32), antinuclear antibodies negativep and IgM rheumatoid factor positive (titre 1/32). An $x$ raf examination of her hands and feet showed periarticulap osteoporosis.

She was treated with bed rest, splintage of the inflamed. joints, and non-steroidal anti-inflammatory drugs. The response was incomplete and in December 1987 treatmen was started with sulphasalazine. Her arthritis respondef and by March 1988 her early morning stiffness was minima? and her joints were quiescent. Her haemoglobin was $15 \Phi$ $\mathrm{g} / \mathrm{l}$, ESR $7 \mathrm{~mm} / \mathrm{h}, C$ reactive protein $60 \mathrm{mg} / \mathrm{l}$, and serurf albumin and globulin were 49 and $27 \mathrm{~g} / 1$ respectively. Hex IgM rheumatoid factor remained positive (titre 1/64).

Our patient satisfied the American Rheumatisn Association 1987 revised criteria for the classification of rheumatoid arthritis. ${ }^{3}$ She had a severe local reaction afte the second dose of the toxoid; a not uncommon side effece the incidence of which increases with the age of the subjects and is more common in women. Those who develop severe reactions frequently have high titres of the circulating antitoxin. ${ }^{4}$ It could well be that the $B$ cell proliferation prat followed the vaccination might have precipitated the onset of RA in our patient, who might have been geneticâlly predisposed. Although one cannot draw too conclusions from one isolated case, there was a stron temporal relation between the introduction of the vaccinen the development of the severe local reaction, and the onser of RA.

Dept of Rheumatology,

Norfolk and Norwich Hospital,

A S M JAWAD

Brunswick Road,

Norwich

Norfolk NR1 3SR

References

1 Turner-Stokes L, Isenberg D A. Immunisation of patients with rheumatoid arthritis and systemic lupus erythematosus. An Rheum Dis 1988; 47: 529-31.

2 Ayvazian L F, Badger T L. Disseminated lupus erythematosu occurring among student nurses. $N$ Engl J Med 1948; 239: 565

3 Arnett F C, Edworthy S M, Bloch D A, et al. The Americad Rheumatism Association 1987 revised criteria for the classi: fication of rheumatoid arthritis. Arthritis Rheum 1988; 3r. $315-24$

4 ABPI data sheet compendium 1988-1989. London: Datapharni Publications, 1988: 1647.

\section{Lymphoma chemotherapy as remission inducing treatment in rheumatoid arthritis}

SIR, I read with interest the article by Cohen et al on the 